\title{
Bisphosphonate Use in Childhood
}

\author{
Jomaa Olfa ${ }^{1 *}$, Jguirim Mahbouba ${ }^{1}$, Rim Kliii ${ }^{2}$, Ardhaoui Mahbouba ${ }^{1}$, \\ Bejia Ismail $^{1}$, Touzi Monji ${ }^{1}$, Bergaoui Naceur ${ }^{1}$ \\ ${ }^{1}$ Department of Rheumatology, University of Monastir, Fattouma Bourguiba \\ Hospital, Tunisia \\ ${ }^{2}$ Department of Internal Medicine, University of Monastir, Fattouma Bourguiba \\ Hospital, Tunisia
}

*Corresponding Author: Jomaa Olfa, Department of Rheumatology, University of Monastir, Fattouma Bourguiba Hospital, Tunisia.
Received: August 30, 2021

Published: September 18, 2021

(C) All rights are reserved by Jomaa Olfa., et al.

\begin{abstract}
Bisphosphonates are structural analogues of inorganic pyrophosphate that are potent inhibitors of bone resorption. In pediatric rheumatology, the main indications of bisphosphonates are primary osteoporosis as idiopathic juvenile osteoporosis, osteogenesisimperfecta, osteoporosis secondary to chronic rheumatological, endocrine, immobilization, or gastrointestinal disorders, tissucalcinosis and dermatomyosistis.

Several pediatric studies have been conducted, mainly in osteogenesis imperfecta and chronic rheumatic diseases. The results obtained with bisphosphonates, especially with pamidronate and alendronate were promising. The use of bisphosphonates should be reserved for children severely affected by a symptomatic osteoporosis. These children should be included in clinical studies with long term monitoring. The regimens reported were cyclic infusion of pamidronate at 0,5 to $1 \mathrm{mg} / \mathrm{kg} / \mathrm{dose}$ with a cumulative dose not exceeding $9 \mathrm{mg} / \mathrm{kg} /$ year. The dose suggested for alendronate were $5 \mathrm{mg}$ once daily or $35 \mathrm{mg}$ once a week for children less than $30 \mathrm{~kg}$ and $10 \mathrm{mg}$ once daily or $70 \mathrm{mg}$ once weekly for more than $30 \mathrm{~kg}$. Treatment protocols must be defined especially with recent bisphosphonates, particularly effectives.
\end{abstract}

Suppose efficacy and tolerability of bisphosphonates in short terms are encouraging. In that case, the duration of treatment and the long-term toxicity, especially in subsequent pregnancies, require further studies.

Keywords: Osteoporosis; Osteogenesisimperfecta; Children; Bisphosphonates; Pediatric DXA; Pamidronate

\section{Introduction}

There is currently a considerable interest in pediatric bone pathology, particularly osteoporosis for many reasons: the development of accurate bone mineralization measurement methods that can be used in children, particularly biphotonic absorptiometry; the advances in our bone metabolism knowledge, the availability of new biological markers of this metabolism, and the appearance of effective molecules in pediatric osteoporosis treatment, in addition to bisphosphonates (BS).

Osteoporosis in children has various origins. In addition to constitutional bone diseases such as osteogenesis imperfecta, general, 
metabolic and endocrine diseases impact on bone tissue, without forgetting drug-induced osteoporosis [1].

BS used in clinical practice for more than 30 years are synthetic analogs of pyrophosphate, which is a natural inhibitor of bone resorption. Once attached to the hydroxyapatite crystals of the bone mineral structure, they increase their resistance, decrease bone turnover by reducing osteoclast activity and longevity by direct effect and by stimulating osteoblasts to produce an inhibitor of osteoclast formation by indirect effect [2,3]. They are widely used in adults. The BS use in pediatrics is diverse but much more limited.

The follow-up of patients treated by BS and the development of new generations of BS with less inhibitory effects on bone mineralization have made it possible to extend their use, especially in childhood osteoporosis, whatever the cause [4].

\section{Structure and pharmacology of bisphosphonates}

BS are synthetic analogues of pyrophosphates where the P-O-P link is replaced by a P-C-P link. These molecules are differentiated from each other by the side chains structure R1 and R2. The BS diversity is explained in (Figure 1) [5]. The BS are divided into three groups that have different action mechanisms. The first group includes BS without nitrogen atom (Clodronate, Etidronate) which belongs to the less potent first generation BS. The BS in the second group are nitrogen-containing (Alendronate, Pamidronate) which are 10 to 100 times more potent than those of the first generation. There is a third generation of BS (risedronate, zoledronic acid) which contain a nitrogen atom in a heterocyclic ring, and are up to 10,000 times more powerful [3].

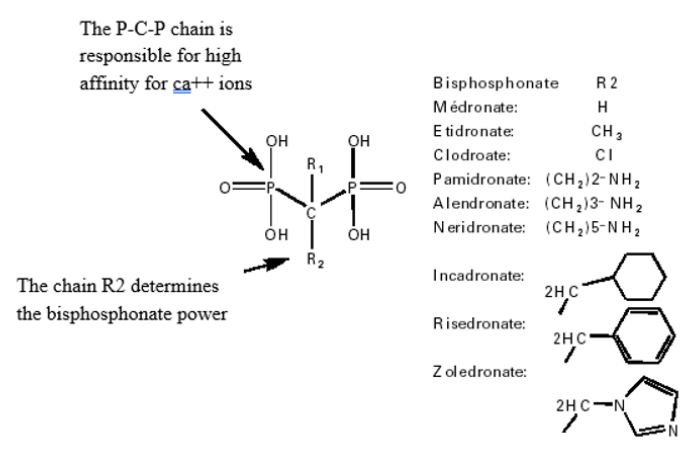

Figure 1: Chemical structure of bisphosphonates [5].
In terms of pharmacokinetics, they are characterized by an extremely long skeletal half-life. That of alendronate, for example, is 10.9 years. Given their common basic chemical structure, all BSs have similar pharmacokinetics.

They have a low biological availability if administered orally $<<$ $6 \%$ ). Binding in bone tissue is approximately $50 \%$, while the excess ( $35 \%$ to $80 \%$ depending on the product) is eliminated in the urine within a few hours without passing into the skeleton $[6,7]$.

Able to resist enzymatic hydrolysis by phosphatases, these molecules are eliminated in the urine without being metabolized. The half-life of bone elimination is very long, from a few weeks to several months or even years, depending on the rate of bone turnover.

Finally, bone vascularization has an important impact on BS biodistribution, which will mostly move to well-perfused bone territories, and consequently, their distribution is greater in trabecular bone than in cortical bone [8,9]. The main BS currently available, dose and mode of administration are given in (Table 1).

\begin{tabular}{|c|c|}
\hline First generation & Presentation \\
\hline Etidronic acid & $\begin{array}{c}\text { OR: Tablet } 200 \text { et } 400 \mathrm{mg} \\
\text { IV: NA }\end{array}$ \\
\hline Second generation & Presentation \\
\hline Pamidronate & IV: $15,60,90 \mathrm{mg}$ \\
\hline Clodronic acid & $\begin{array}{l}\text { OR: capsule } 400 \mathrm{mg} \\
\text { IV: } 300 \mathrm{mg}\end{array}$ \\
\hline Tiludronic acid & OR: Tablet $200 \mathrm{mg}$ \\
\hline Third generation & Presentation \\
\hline Ibandronic Acid & IV: $2 \mathrm{mg}$ \\
\hline Alendronate & OR: Tablet $10 \mathrm{mg}$ \\
\hline $\begin{array}{l}\text { Monosodium isozoledro- } \\
\text { nate }\end{array}$ & IV: $4 \mathrm{mg}$ \\
\hline Risedronic Acid & OR: Tablet $5 \mathrm{mg}$ \\
\hline $\begin{array}{l}\text { Olpadronic acid } \\
\text { Neridronic acid }\end{array}$ & $\begin{array}{l}\text { NA } \\
\text { NA }\end{array}$ \\
\hline
\end{tabular}

Table 1: Bisphosphonates available in Europe OR: Oral Route; IV: Intravenous; gel: Capsules; NA: Not Available.

\section{Main indications of bisphosphonates in pediatrics}

Juvenile osteoporosis includes, constitutional bone fragility dominated by osteogenesis imperfecta on the one hand, and, on the 
other hand, secondary osteoporosis due to long term corticosteroid therapy. This second etiology is constantly increasing due to the progressive improvement in life expectancy of children treated for cancer or chronic inflammatory diseases [1,10-12].

For curative purposes, BS use in children is more diverse than in adults. The first uses in children concerned hypercalcemia and Progressive Ossifying Myositis. They have expanded over the last ten years, and osteoporosis with bone fragility is the most common indication [13]. Prophylactic use of BS does not currently have a consensus in pediatric diseases and is not recommended. The most important BS indications are given in (Table 2).

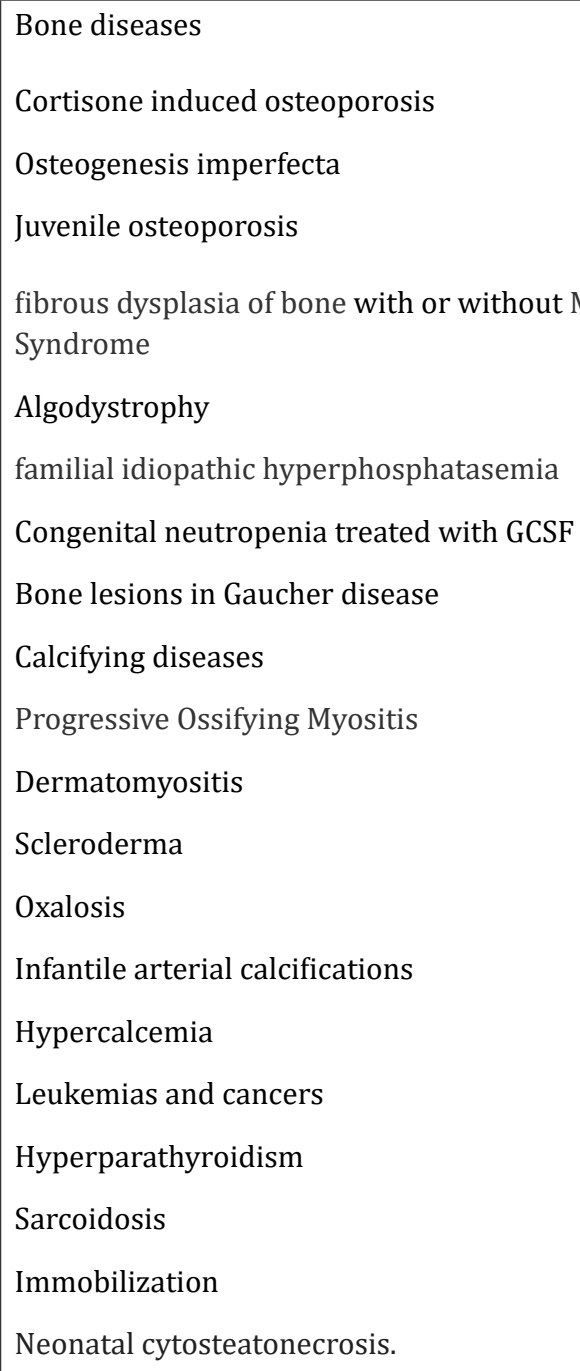

Table 2: Indications for biphosphonates [1].

\section{Osteogenesis imperfecta}

It is a disease characterized by a significant bone fragility related to generalized osteoporosis and responsible for fractures or bone deformities. The osteogenesis imperfecta prognosis varies greatly from one form to another, but better orthopedic and medical management in addition to BS use has improved their outcome and especially patients life quality [14].

Many studies in children report the results of pamidronate cures given annually at a dose of $9 \mathrm{mg} / \mathrm{kg}$. Chronic pain is significantly reduced and disappears after 2 to 3 cures. An increased muscular strength and an improvement in functional abilities have been reported [15]. The reduction in long bone fracture rate remains difficult to assess because many factors are involved. Two studies have shown a $65 \%$ decrease in the incidence of long bone fractures $[16,17]$.

At usual doses, pamidronate does not disturb growth, Zeitlin., et al. even report a significant improvement [18]. Indeed, lumbar vertebral bone mass increases faster than in untreated patients. Some spinal fracture regain near-normal size [18].

Each pamidronate cure is marked with a radiological metaphyseal band which corresponds to secondarily calcified bone trabeculae in horizontal position [18].

Recently, Ward., et al. evaluated alendronate given for two years in 109 patients with osteogenesis imperfecta types I, III or IV compared to a 30 patients group with osteogenesis imperfecta treated with placebo.

Patients received $5 \mathrm{mg}$ /day of alendronate if weight was less than $40 \mathrm{~kg}$ and $10 \mathrm{mg} /$ day if weight was over $40 \mathrm{~kg}$. Spinal bone mineral density increased by $51 \%$ in the alendronate group versus $12 \%$ in the placebo group ( $\mathrm{p}<0,001)$ and the Z-score increased from -4.6 to $-3.3 \mathrm{SD}$ in the alendronate group. The Collagen type I $\mathrm{N}$-terminal telopeptide (NTX) level, which is a marker of urinary bone remodeling, decreased by $62 \%$ in the treated group versus $32 \%$ in the untreated group [19].

Zoledronic acid was also tested in a study including 17 patients with osteogenesis imperfecta type I aged 1.5 to 16.8 years. It was administered at a dose of $0.05 \mathrm{mg} / \mathrm{kg}$ for 1 to 3.2 years as a $30-\mathrm{min}$ ute intravenous infusion every 6 months. Spinal mineral density 
increased from -2 to -0.7 SD after two years of treatment [20]. Other studies have shown that zoledronic acid reduces the risk of fractures [21-23].

Ibandronate was also used in 30 patients with osteogenesis imperfecta. Two groups were compared: the first group received infusions of Ibandronate $2 \mathrm{mg}$ every 3 months. The second control group received $0.2 \mu \mathrm{g}$ calcitriol. After a year of treatment, the fracture risk decreased from 1.9 to 1.13 for the first group and from 1.8 to 1 for the second group. A significant increase in bone mineral density was noted at all sites: $59 \%$ in the lumbar spine and $36.6 \%$ in the hip. Alkaline phosphatases and Collagen type I C-terminal telopeptide (CTX) were also significantly reduced.

Neridronate has been available since a few years. In placebocontrolled trials, it has been shown to be effective in raising bone mineral density and minimizing the fracture risk [21,24]. It has been used at a dose of $2 \mathrm{mg} / \mathrm{kg}$ intravenously every 3 months [25]. It is actually the most widely used BS in Germany [26].

Based on the results of a single study comparing neridronate to pamidronate, there was no significant difference between the two groups in terms of increased patient size and vertebral surfaces $(p$ $=0.530$ ) [27].

\section{Cortisone induced osteoporosis}

Bone mass loss associated with corticosteroid use is rapid: about $12 \%$ during the first three months of corticosteroid therapy, then about $3 \%$ annually [4]. A study of 38 children with connective tissue diseases showed that alendronate (5 mg daily orally for one year) had a beneficial effect on bone mineral density (BMD) [28]. The mean increase in Z-score from baseline was $1.49 \pm 0.98 \%$ in the treated group $(\mathrm{p}<0,002)$, while no significant increase was observed in the control group.

In a second study including 22 children aged 4.4 to 17.2 years with chronic diseases (juvenile arthritis, systemic lupus erythematosus) treated with long-term corticosteroid therapy, alendronate was used for one year at a dose of 1 to $2 \mathrm{mg} / \mathrm{kg} /$ week orally (dose rounded up to 40 or $80 \mathrm{mg}$ depending on weight) for 12 months. A positive effect was reported on spinal bone density $(p=0.013)$ and also on bone growth [29].

In the same study, alendronate was also studied versus placebo in the prevention of cortisone-induced osteoporosis with excellent results. The recommended dose for this indication is 1 to $2 \mathrm{mg} / \mathrm{kg}$ per week (35 mg if weight $\geq 30 \mathrm{~kg}, 25 \mathrm{mg}$ for $20 \mathrm{~kg}<$ weight $<30 \mathrm{~kg}$, $15 \mathrm{mg}$ for $15 \mathrm{~kg}<$ weight $<20 \mathrm{~kg}$ ) [29-31].

The BS treatment has to be started early, as soon as a prolonged corticosteroid therapy is instituted. Maximum bone loss is observed within the first 3 months [29].

Another study conducted on 18 children treated with pamidronate, a single infusion every three months resulted in a spinal density increasing with a reduced fractures risk by 6 months of treatment [32].

A recent study evaluated the effect of intravenous zoledronic acid in 20 children aged 3 to 16 years with a diverse range of bone diseases (corticosteroid secondary osteoporosis, immobilization osteoporosis, primary idiopathic osteoporosis, Gaucher disease and neurofibromatosis type 1 ). Doses administered were $0.1 \pm 0.02$ $\mathrm{mg} / \mathrm{kg} /$ dose infused every three months for an average of $1.7 \pm 0.7$ years. The Z-score in the spine improved by 1.88 after 12 months of treatment [33].

\section{Hypercalcemia}

In childhood, etidronate, pamidronate and intravenous clodronate have been used successfully previously [34]. Pediatric experience with severe hypercalcemia is restricted and concerns small series [34]. All reported cases have been successfully handled, mainly by pamidronate. In general, the recommended dose of pamidronate is $0.5 \mathrm{mg} / \mathrm{kg} /$ day (children $>2$ years) to $1 \mathrm{mg} / \mathrm{kg} /$ day (children $<2$ years) intravenously over 2 to 4 hours allows normalization of serum calcium levels in 1 to 4 days. This dose may be repeated for several consecutive days. There is a dose-response relationship between bisphosphonates and decreased serum calcium levels [7,35-37].

Recently used, zoledronic acid is considered more potent and effective than pamidronate [38] and has been used in children with bone metastasis [39] with good results. It is generally well tolerated with side effects similar to those observed with pamidronate. We should consider the use of zoledronic acid as a rapid, potent, safe and effective therapy in hypercalcemia of malignant tumors in children $[22,40]$. 


\section{Bone fibrous dysplasia}

Osteoporosis in this disease is multifactorial : it includes corticosteroid use, vitamin D malabsorption, inflammation, malnutrition, delayed puberty and reduced physical activity. The results of BS treatment in children with more severe forms are more mitigated. Intravenous pamidronate has been used in pediatric cases of isolated fibrotic dysplasia or MacCune Albright syndrome [32,38,39]. And it has shown clinical improvement, a decrease in bone remodeling as well as radiological remodeling of bone lesions [3,4,7]. A few series currently offer oral BS treatment for chronic pain, such as alendronate given at a dose of $70 \mathrm{mg} /$ week [41].

\section{Dermatomyositis calcifications}

Rare cases of regression of calcification sites with BS have been reported [7]. The efficiency of BS was proved in a 14-year-old girl who had been suffering from calcifying juvenile dermatomyositis since the age of 11 . She was treated with pamidronate for two years (15 mg every three months in the first year, then $30 \mathrm{mg}$ every four months in the second year, equivalent to $2 \mathrm{mg} / \mathrm{kg}$ per year) [42].

A significant improvement in clinical signs (pain, subcutaneous induration and hip mobility) began two months after the initiation of Pamidronate. The resolution of all visible calcifications characterized the post-treatment assessment. The same positive effect has already been described under Alendronate in two six-year-old children $[43,44]$.

A recent publication [45] reports a successful effect of alendronate $(10 \mathrm{mg} / \mathrm{d}$ for one year) in a ten-year-old child with extensive calcinosis: calcification disappears and significant functional recovery of the joints, with no side effects [4].

\section{Other osteoporosis}

BS (mainly intravenous pamidronate) has been used in pediatric observations of secondary osteoporosis, juvenile idiopathic osteoporosis, and familial hyperphosphatasia.

Pre-therapeutic investigation and modalities of bisphosphonate administration

Investigations are required before starting treatment with BS, including phosphocalcium balance, creatininemia, albuminemia, osteoformation markers (alkaline phosphatases, osteocalcin) and resorption markers (hydroxyprolinuria, pyridinoline, deoxypyr- idinoline), and measurements of parathyroid hormone and 25-hydroxyvitamin D.

Also, standard radiographs of the spine and fractured long bones are necessary. Bone densitometry is used mostly to be a comparative model in the same patient before and after BS treatment. In case of oral BS treatment, some recommendations should be provided to patients and parents: treatment should be taken with a large glass of water only in the morning, do not lie down for one hour, do not eat for 30 minutes. A calcium supplement should be prescribed for all osteopenic and osteoporotic patients.

Osteoporosis prevention is mainly based on lifestyle practices: a balanced diet, a body mass index within the norms, sufficient physical activity, and limiting the factors that promote osteoporosis. Patients must have an appropriate vitamin and calcium supplementation (Calcium: 1000-1200 mg/d and Vitamin D: 400-800 IU/d).

\section{Modalities of bisphosphonate administration}

As their intestinal absorption is low $(<10 \%)$, the intravenous route is preferred in most pediatric studies. In osteoporosis, the most widely used protocol is that recommended by Glorieux., et al. [46], which involves intravenous infusions of $0.5-1 \mathrm{mg} / \mathrm{kg} / \mathrm{d}$ of pamidronate 3 days consecutively every 4 months for at least 1 year.

Good results have also been reported in osteogenesis imperfecta with a protocol using intravenous infusion of pamidronate repeated at 3-month intervals [32]. In infants under the age of 3 years, more frequent infusions with a lower dose are common [47]. Indeed, the accelerated bone turnover in infants results in earlier, greater, but less prolonged efficacy of bisphosphonates.

A trial assessed the results of two regimens of intravenous pamidronate administered to 15 children diagnosed with various diseases excluding osteogenesis imperfecta. The first group received a dose of $1 \mathrm{mg} / \mathrm{kg}$ given as a single day every three months without exceeding a total dose of $4 \mathrm{mg} / \mathrm{kg} /$ year. The second group received three-day infusions every 4 months at a $1 \mathrm{mg} / \mathrm{kg}$ dose without exceeding $9 \mathrm{mg} / \mathrm{kg} /$ year.

There was no significant difference between the two groups in terms of increased bone densitometry and decreased fracture rates [48]. Alendronate, an orally administered BS, is given according to patient characteristics. Suggested doses in most studies are $5 \mathrm{mg}$ 
once daily or $35 \mathrm{mg}$ once weekly for children weighing $30 \mathrm{~kg}$ or less, and $10 \mathrm{mg}$ once daily or $70 \mathrm{mg}$ once weekly for children of more than $30 \mathrm{~kg}$ [13]. TZoledronate, is given as short infusions (2030 minutes vs. 4 hours for pamidronate) at a dose of 0.02-0.05 mg/ $\mathrm{kg} / \mathrm{d}$ every 3 months [13].

\section{Subcutaneous bisphosphonates}

Intravenous pamidronate is safe and well tolerated in children, but may have side effects if given subcutaneously [49]. Clodronate has been tried at a dose of $300 \mathrm{mg}$ given as a single monthly injection subcutaneously in a child with a severe bone pain due to Ewing's sarcoma. For zoledronic acid, there were no data on its use by the subcutaneous route.

\section{Do we treat all children with osteoporosis?}

Pediatric osteoporosis definition refers to bone density assessment by Dual Photon Absorptiometry [38]. In children, bone density is age related, and osteoporosis can be defined by a Z-score value of less than -2 SD, osteopenia by a value between -1 and - 2 SD adjusted for age, gender, and height [10-12,50].

Obviously, a short child will always have a lower result than a child of a same age and normal height. Consequently, we have to compare the results of a patient with those of patients of the same height, which means that statural age must be considered. The puberty status is probably also to be considered. In addition, it should be noted that there are no normal values for children under three years old.

Patients with fragile bones ( 2 to 3 fractures per year in the previous 2 years, often spontaneous fractures) with severe osteoporosis as assessed by bone densitometry, the use of BS intravenously should be recommended. The use of BS before six months of age is recommended in these patients to prevent the fracture-immobilization-fragilization-fracture vicious circle [51].

The treatment of osteoporosis discovered during follow-up in a child with systemic disease or treated with corticosteroids is more difficult. Bone pain, even without fractures, is a criteria for treatment with BS, as these drugs have been shown to be effective on bone pain.

Similarly, high levels of bone remodeling biomarkers should always be considered according to their evolution and the child's age. A low BMD without bone fragility or pain does not necessarily lead to the BS prescription. The studies currently available are too limited to confirm the usefulness of BS in preventing complications of osteoporosis in adults.

\section{Adverse effects of bisphosphonates}

Oral treatments may cause digestive disorders, including esophageal, gastric and duodenal ulcerations. Bands of sclerosis may also be seen on X-ray, which have no structural or functional impact [52,53]. These metaphyseal sclerosis bands disappear once the treatment is stopped and No impact on growth has been found [54].

Pamidronate has few side effects. Within 24 to 72 hours after administration, whether oral or intravenous, an influenza-like syndrome (fever, myalgias, diffuse pain, nausea, vomiting) with a biological inflammatory syndrome may be observed $[25,37,48,55]$.

These two immediate side effects may require symptomatic treatment with conventional analgesics or anti-inflammatory drugs and justify interruption of pamidronate injections. Usually these symptoms are unnoticed during later infusions $[14,54,56]$.

The long-term outcome was characterized by the occurrence of mineralization disorders, which have been reported with pamidronate. Indeed, a case of osteopetrosis has been reported in a child after prolonged use of high doses of pamidronate [14,57]. Hegazy., et al. [61] noted unusual femur stress fractures after long-term bisphosphonate therapy (6-11 years); among 72 children receiving intravenous pamidronate, 18 had a femur fracture.

A rapid weight gain has been noted in many children treated with pamidronate. This unexplained obesity interferes with their rehabilitation. Similar findings have been noted with alendronate [58]. The occurrence of uveitis was noted by Glorieux twice in 215 treated children. BS may delay bone healing after surgical osteotomy and intramedullary nailing [59]. In the case of planned osteotomies, a treatment-free preoperative period should be arranged. Generally, all side effects observed with BS are reversible once the treatment is stopped.

Osteonecrosis of the jaw reported in adults is another rare adverse effect of BS in children $[14,45,60]$. Despite the rarity of osteonecrosis of the jaw cases in children treated with BS, it is rec- 
ommended to improve the oral health of these children before initiation of treatment, in order to access the necessary invasive care (extraction,....) [54]. Regular dental assessments by a dentist during treatment and good daily oral hygiene are required [14, 37, 54, 61-63].

\section{Conclusion}

BS are an effective treatment for peadiatric osteoporosis and have few side effects. However, their use remains limited due to the lack of product approval and many controversies. Points that need to be clarified are initiation criteria for curative or preventive treatment, the optimal duration of treatment, the dose and frequency of administration, and the relative indications of each bisphosphonate. Controlled multicenter studies comparing various drugs with different routes of administration are essential in order to definitively validate their use. In addition, their long-term side effects, essentially related to their prolonged and strong binding to the bone, must be evaluated by studies including a long-term followup.

\section{Bibliography}

1. Delalande D., et al. "Les ostéoporoses juvéniles Juvenile osteoporosis". Archives of Pediatrics 15.4 (2008): 420-30.

2. Russell RG. "Bisphosphonates: mode of action and pharmacology". Pediatrics 119.2 (2007): 150-162.

3. Batch JA., et al. ". Use of bisphosphonatetherapy for osteoporosis in childhood and adolescence". Journal of Paediatrics and Child Health 39.2 (2003): 88-92.

4. Kone Paut I., et al. "Les biphosphonates chez l'enfant: présent et avenir Biphosphonates in children: present and future". Archives of Pediatrics 9.8 (2002): 836-842.

5. Abi Najm S., et al. "Bisphosphonates-related jaw osteonecrosis: mise au point". Medecine Buccale Chirurgie Buccale 14 (2008): 5-18.

6. Papapoulos SE and Cremers SC. "Prolonged bisphosphonate release after treatment in children". The New England Journal of Medicine 356.10 (2007): 1075-1076.

7. Sebestyen JF., et al. "Bisphosphonates use in children". Clinical Pediatrics (Phila) 51.11 (2012): 1011-1024.
8. Ezra A and Golomb G. "Administration routes and delivery systems of bisphosphonates for the treatment of bone resorption". Advanced Drug Delivery Reviews 42.3 (2000): 175-195.

9. Russell RG., et al. "Bisphosphonates: pharmacology, mechanisms of action and clinical uses". Osteoporosis International 9.2 (1999): 66-80.

10. Dorgeret S., et al. "L’ostéodensitométrie en pratique pédiatrique Bone densitometry in pediatric practice". JBR-BTR 88.5 (2004): 263-4.

11. Gafni RI and Baron J. "Overdiagnosis of osteoporosis in children due to misinterpretation of dual-energy x-ray absorptiometry (DEXA)". Journal of Pediatrics 144.2 (2008): 253-257.

12. Hogler W., et al. "Importance of lean mass in the interpretation of total body densitometry in children and adolescents". Journal of Pediatrics 143.1 (2003): 81-88.

13. Bachrach LK and Ward LM. "Clinical review 1: Bisphosphonate use in childhood osteoporosis". The Journal of Clinical Endocrinology and Metabolism 94.2 (2009): 400-409.

14. Wood CL and Ahmed SF. "Bone protective agents in children". Archives of Disease in Childhood 103.5 (2018): 503-508.

15. Rauch F and Glorieux FH. "Bisphosphonate treatment in osteogenesis imperfecta: which drug, for whom, for how long?" Annals of Medicine 37.4 (2005): 295-302.

16. Forin V., et al. "Benefits of pamidronate inchildren with osteogenesis imperfecta : an open prospective study". Joint Bone Spine 72.4 (2005): 313-318.

17. Ward LM., et al. "A randomized placebo controlled trial of oral alendronate children and adolescents with osteogenesis imperfecta". Journal of Bone and Mineral Research 20 (2005): S1S102.

18. Zeitlin L., et al. "Height and weight development during four years of therapy with cyclical intravenous pamidronate in children and adolescents with osteogenesis imperfecta types I, III, and IV". Pediatrics 111.5 (2003): 1030-1036.

19. Ward LM., et al. "Alendronate for the treatment of pediatric osteogenesis imperfecta: a randomized placebo-controlled 
study". The Journal of Clinical Endocrinology and Metabolism 96.2 (2011): 355-364.

20. Vuorimies I., et al. "Zoledronic acid treatment in children with osteogenesis imperfecta". Hormone Research in Paediatrics 75.5 (2011): 346-353.

21. Saraff V and Högler W. "ENDOCRINOLOGY AND ADOLESCENCE: Osteoporosis in children: diagnosis and management". European Journal of Endocrinology 173.6 (2015): R185-197.

22. Kolyva S., et al. "Hypercalcemia and osteolytic lesions as presenting symptoms of acute lymphoblastic leukemia in childhood. The use of zoledronic acid and review of the literature". Journal of Pediatric Endocrinology and Metabolism 27.3-4 (2011): 349-354.

23. Saraff V., et al. "Efficacy and treatment costs of zoledronate versus pamidronate in paediatric osteoporosis". Archives of Disease in Childhood 103.1 (2018): 92-94.

24. Semler 0., et al. "Reshaping of vertebrae during treatment with neridronate or pamidronate in children with osteogenesis imperfecta". Hormone Research in Paediatrics 76.5 (2011): 321-327.

25. Gatti D., et al. "Intravenous neridronate in children with osteogenesis imperfecta: a randomized controlled study". Journal of Bone and Mineral Research 20.5 (2005): 758-763.

26. Hoyer-Kuhn H., et al. "Osteogenesis imperfecta: pathophysiology and treatment". Wien Med Wochenschr 165.13-14 (2015): 278-284.

27. Semler 0., et al. "Reshaping of vertebrae during treatment with neridronate or pamidronate in children with osteogenesisimperfecta”. Hormone Research in Paediatrics 76.5 (2011): 321327.

28. Bianchi Ml., et al. "Efficacity and safety of alendronate for the treatment of osteoporosis in diffuse connective tissue diseases in children : a prospective multicenter study". Arthritis Rheum 43 (2000): 1960-1966.

29. Rudge S., et al. "Effects of once-weekly oral alendronate on bone in children on glucocorticoidv treatment". Rheumatology
44.6 (2005): 813-818.

30. Bianchi ML., et al. "Treatment of low bone density in young people with cysticfibrosis: a multicentre, prospective, openlabel observational study of calcium and calcifediol followed by a randomised placebo-controlled trial of alendronate". Lancet Respiratory Medicine 1.5 (2013): 377-385.

31. Ward LM., et al. "The management of osteoporosis in children". Osteoporosis International 27.7 (2016): 2147-2179.

32. Steelman J and Zeitler P. "Treatment of symptomatic pediatric osteoporosis with cyclic single-day intravenous pamidronate infusions". Journal of Pediatrics 142.4 (2003): 417-423.

33. Simm PJ., et al. "Zoledronic acid improves bone mineral density, reduces bone turnover and improves skeletal architecture over 2 years of treatment in children with secondary osteoporosis". Bone 49.5 (2011): 939-943.

34. Lteif AN and Zimmerman D. "Bisphosphonates for treatment of childhood hypercalcemia". Pediatrics 102 (1998): 990-993.

35. Kerdudo C., et al. "Hypercalcémie chez l'enfant cancéreux". Archives de pédiatrie 12.6 (2005): 691-693.

36. Poirée M., et al. "Hypercalcémie menaçante révélatrice d'une leucémie aiguë lymphoblastique de l'enfant". Archives de pédiatrie 22.6 (2015): 608-612.

37. Guarino S., et al. "An infant with hypercalcemia: answers". Pediatric Nephrology 29.11 (2014): 2123-2125.

38. Saggese G., et al. "Osteoporosis in children and adolescents: diagnosis, risk factors, and prevention". Journal of Pediatric Endocrinology and Metabolism 14.7 (2001): 833-859.

39. Gandrud LM., et al. "Low-dose intravenous pamidronate reduces fractures in childhood osteoporosis". Journal of Pediatric Endocrinology and Metabolism 16.6 (2003): 887-892.

40. Dhivyasree S., et al. "A rare and unusual presentation of acute lymphoblastic leukemia". Journal of Cancer Research and Therapeutics 14.12 (2018): 1244-1246.

41. Aragão AL., et al. "Oral Alendronate Treatment for Severe Polyostotic Fibrous Dysplasia due to McCune-Albright Syndrome 
in a Child: A Case Report". International Journal of Pediatric Endocrinology 2010 (2010): 432060.

42. Slimani S., et al. "Résolution complète d'une calcinose universelle compliquant une dermatomyosite juvénile traitée par pamidronate". Revue du rhumatisme 77.1 (2010): 91-93.

43. Mukamel M., et al. "New insight into calcinosis of juvenile dermatomyositis: a study of composition and treatment". Journal of Pediatrics 138.5 (2001): 763-766.

44. Ambler GR., et al. "Rapid improvement of calcinosis in juvenile dermatomyositis with alendronate therapy". Journal of Rheumatology 32.9 (2005): 1837-1839.

45. Rothenbuhler A., et al. "Risk of corrected QT interval prolongation after pamidronate infusion in children". The Journal of Clinical Endocrinology and Metabolism 95.8 (2010): 37683770 .

46. Glorieux FH., et al. "Cyclic administration of pamidronate in children with severe osteogenesis imperfecta". The New England Journal of Medicine 339.14 (1998): 947-952.

47. Plotkin H., et al. "Pamidronate treatment of severe osteogenesis imperfecta in children under 3 years of age". The Journal of Clinical Endocrinology and Metabolism 85.5 (2000): 18461850.

48. Martinez-Soto T., et al. "Treatment of symptomatic osteoporosis in children: a comparison of two pamidronate dosage regimens". The Journal of Clinical Endocrinology and Metabolism 24.5-6 (2011): 271-274.

49. Siden H. "The boy who refused an IV: a case report of subcutaneous clodronate for bone pain in a child with Ewing Sarcoma". Journal of Medical Case Reports 21.1 (2007): 7.

50. Bishop N., et al. "Fracture prediction and the definition of osteoporosis in children and adolescents: the ISCD 2013 Pediatric Official Positions". Journal of Clinical Densitometry 17.2 (2014): 275-280.

51. Plotkin H., et al. "Pamidronate treatment of severe osteogenesis imperfecta in children under 3 years of age". The Journal of Clinical Endocrinology and Metabolism 85.5 (2000): 18461850.

52. Sarraf KM. "Images in clinical medicine. Radiographic zebra lines from cyclical pamidronate therapy". The New England Journal of Medicine 365.3 (2011): e5.

53. Szadek LL and Scharer K. "Identification, prevention, and treatment of children with decreased bone mineral density". Journal of Pediatric Nursing 29.5 (2014): e3-14.

54. Soybilgic A., et al. "A survey of steroid-related osteoporosis diagnosis, prevention and treatment practices of pediatric rheumatologists in North America". Pediatric Rheumatology 12 (2014): 24.

55. Ward LM., et al. "Single-dose pharmacokinetics and tolerability of alendronate 35- and 70-milligram tablets in children and adolescents with osteogenesis imperfecta type I". The Journal of Clinical Endocrinology and Metabolism 90.7 (2005): 40514056.

56. Whyte MP., et al. "Bisphosphonate-induced osteopetrosis". The New England Journal of Medicine 349.5 (2003): 457-463.

57. Hegazy A., et al. "Unusual Femur Stress Fractures in Children With Osteogenesis Imperfecta and Intramedullary Rods on Long-term Intravenous Pamidronate Therapy". Journal of Pediatric Orthopaedics 36.7 (2016): 757-761.

58. Inoue Y., et al. "Efficacy of intravenous alendronate for the treatment of glucocorticoid-induced osteoporosis in children with autoimmune diseases". Clinical Rheumatology 27.7 (2008): 909-912.

59. Kan SL., et al. "Alendronate prevents glucocorticoid-induced osteoporosis in patients with rheumatic diseases: A metaanalysis". Medicine (Baltimore) 95.25 (2016): e3990.

60. Hennedige AA., et al. "Systematic Review on the Incidence of Bisphosphonate Related Osteonecrosis of the Jaw in Children Diagnosed with Osteogenesis Imperfecta". Journal of Oral and Maxillofacial Research: JOMR 4.4 (2014): e1.

61. Malmgren B., et al. "No osteonecrosis in jaws of young patients with osteogenesis imperfecta treated with bisphosphonates". Journal of Oral Pathology and Medicine 37.4 (2008): 196-200. 
62. Brown JJ., et al. "Bisphosphonate-associatedosteonecrosis of the jaw: doesitoccur in children?". Clinical Endocrinology (Oxf) 68.6 (2008): 863-867.

63. Lietman SA., et al. "Hypercalcemia in children and adolescents". Current Opinion in Pediatrics 22.4 (2010): 508-515.

\section{Volume 5 Issue 10 October 2021}

(C) All rights are reserved by Jomaa Olfa., et al. 